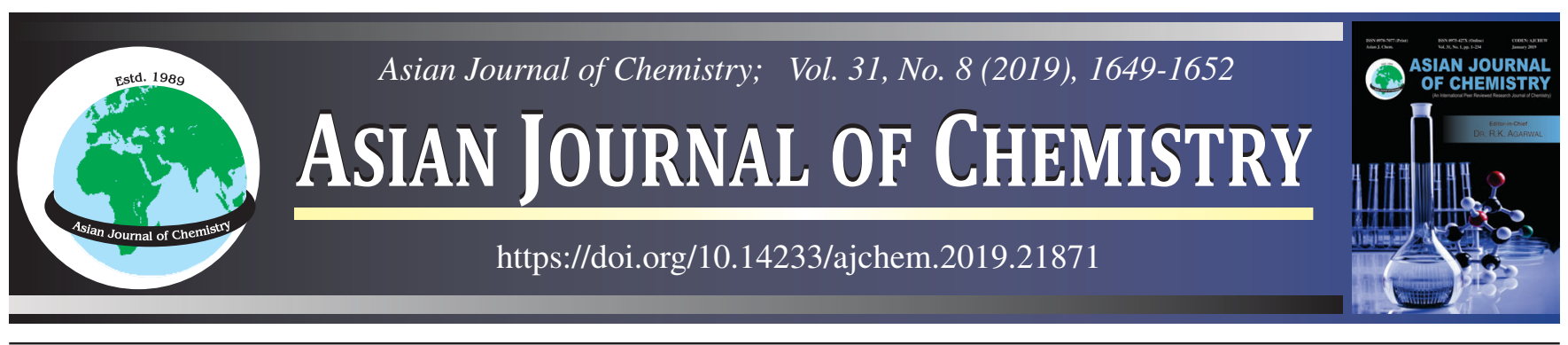

\title{
Identification and Quantification of Germacrene D from the Extracts of Zanthoxylum ovalifolium Leaves by $\mathrm{AgNO}_{3}$-TLC Densitometric Method
}

\section{B.S. Theerthavathy ${ }^{1}$, Shaukath Ara Khanum ${ }^{2}$ and S. Ravi Kiran ${ }^{3, *}$}

${ }^{1}$ Research and Development Centre, Bharathiar University, Coimbatore-641046, India

${ }^{2}$ Department of Chemistry, Yuvaraja's College, Mysore-570005, India

${ }^{3}$ Department of Biochemistry, Aurora's Degree \& P.G. College, Chikkadapally, Hyderabad-500020, India

*Corresponding author: E-mail: srksuripeddi@gmail.com

Received: 10 December 2018;

Accepted: 1 February 2019;

Published online: 28 June 2019;

AJC-19431

Germacrene D an important sesquiterpenoid has been extracted from leaves of Zanthoxylum ovalifoilum and high performance thin-layer chromatographic method has been developed for its simultaneous identification and determination. The compound was extracted by cold extraction and separated and identified on $\mathrm{AgNO}_{3}$ impregnated silica gel $60 \mathrm{~F}_{254}$ HPTLC plates with dichloromethane:acetone (9.8:0.2 $\mathrm{v} / \mathrm{v})$ as mobile phase. The quantification of geremcare $\mathrm{D}$ was carried out by densitometry scanning performed at $\lambda=254 \mathrm{~nm}$ by reflectance scanning. This facilitated a well-resolved band for the compound with a $R_{\mathrm{f}}$ value of $0.46 \pm 0.01$. Linear regression concentration analysis data for mean calibration plots showed good linear relationship in the range of $1000-10000 \mathrm{ng} / \mathrm{mL}$, with a correlation coefficient, slope and intercept of $0.9985 \pm 0.0004,21.62 \pm 0.435$ and $3308.87 \pm 10.24$, respectively. The minimum amount of germacrene D that could be authentically detected (LOD) and quantified (LOQ) were determined and found to be 212.07 and 521.23 ng/spot, respectively. The method was validated by considering the parameters linearity, precision, accuracy, specificity and robustness wherein, it is evident from the results that the proposed method was simple, safe and reliable.

Keywords: Zanthoxylum ovalifolium, HPTLC method, Densitometric scanning, Germacrene D.

\section{INTRODUCTION}

It is well known that medicinal and aromatic plants produce a wide variety of compounds known as secondary metabolites. These compounds are indispensable for the survival of plants but majority of them have wide ecological functions and useful for mankind for implication in various diseases. Besides this, the medicinal plants are reservoir of fine chemicals known as natural products which are of commercial importance. Among these, essential oils form one of the major groups and of potential interest which are nothing but complex mixture of natural products occurring in plants as secondary metabolites, exhibiting characteristic odour and volatile. In recent years, essential oil research has received much attention due to wide range of chemical and biological properties exhibited by majority of these compounds. Sesquiterpenes and particularly sesquiterpene hydrocarbons of the elemental composition $\mathrm{C}_{15} \mathrm{H}_{24}$ are abundant constituents of many plants [1]. Among them, germacrene $\mathrm{D}\left(\mathrm{C}_{15} \mathrm{H}_{24}\right)$ is wide spread in nature and considered to be a key intermediate in the biosynthesis of all sesquiterpenes [2-4]. Researches on germacrene D show that it mimics a pheromone involved in sex of American cockroach that gave antennal and behavioural responses [5]. Further, it has been shown to possess mosquito larvicidal [6] and feeding deterrence [7,8]. Therefore, there is a need for simple, quick and easily applied methods directed towards the analysis of this compound.

Zanthoxylum ovalifolium belongs to the family Rutaceae is an erect shrub or small tree which grows up to 8 metres tall. The plant is distributed in India, Nepal, Pakistan, Myanmar, Indonesia, Papua New Guinea and Australia. Concerning the phytochemistry, the plant is known to possess alkaloids, terpenoids, glycosides, phenols and flavonoids [9]. As evident from the literature, the plant exhibits potential antioxidant, antiinflammatory, natural pesticide, antimicrobial, anthelmintic, hepatoprotective, antiproliferative and antifungal activities $[9,10]$. Based on the comprehensive knowledge and ethnobotanical

This is an open access journal, and articles are distributed under the terms of the Attribution 4.0 International (CC BY 4.0) License. This license lets others distribute, remix, tweak, and build upon your work, even commercially, as long as they credit the author for the original creation. You must give appropriate credit, provide a link to the license, and indicate if changes were made. 
information, germacrene D is isolated, which is an important molecule and developed a method for separation and quantification by HPTLC method. To our best of knowledge there is no published report so far available on the HPTLC method validation of this compound and hence we herein presented the results of the present investigative study.

\section{EXPERIMENTAL}

The chemicals and solvents required for the study were of analytical grade and procured from Merck, India. The standard germcerene D was a gift from Prof. Robin Kinnel, Hamilton,USA.

Sample collection: Leaves of Zanthoxylum ovalifoilum collected from the forest of Malnad region near Hassan city, India where a sample specimen was deposited at herbarium of Department of Botany, A.V.K. College for Women, Hassan, India (No. AVKBOT 4784).

Extraction: The leaves were collected, transferred into a flask and soaked in diethyl ether for cold extraction for about $8 \mathrm{~h}$. After that the leaves were mildly homogenized in a mortar and pestle and the extract was filtered. The filtrate was transferred to a separating funnel and the contents were allowed to stand until there was a separation of two layers. The separated ether layer was dried over anhydrous $\mathrm{Na}_{2} \mathrm{SO}_{4}$, evaporated under vacuum. This yielded a light green oily extract which was stored in a refrigerator until further use.

HPTLC analysis: TLC of light green oily extract was performed on HPTLC aluminum plates $(0.25 \mathrm{~mm}$ thickness $)$ which were pre-coated with $60 \mathrm{~F}_{254} 0.25 \mathrm{~mm}$ (obtained from Merck, Darmstadt, Germany). These plates were further impregnated with $8 \% \mathrm{AgNO}_{3}$ before the start of the experiment. Both standard and sample were spotted on to these plates in the form of bands (6 $\mathrm{mm}$ width) using Linomat $\mathrm{V}$ applicator (Muttenz, Switzerland and procured from Anchrom Technologists, Mumbai, India). This applicator was equipped with a $100 \mu \mathrm{L}$ microsyringe. The sample is applied at a constant rate of $5 \mu \mathrm{L} / \mathrm{s}$ with a distance of $10 \mathrm{~mm}$ between the bands. The dimension of slit at $5 \times 0.45 \mathrm{~mm}$ and scanning speed of $20 \mathrm{~mm} / \mathrm{s}$ were maintained throughout the experiment. The plates were developed in a twin trough chamber (filter paper saturated) using dichloromethane:acetone mobile phase at 9.8:0.2 v/v ratio. The plate was run to a length of $8.5 \mathrm{~cm}$ and after the development, the plates were dried. Then the plates were subjected to densitometric scanning in a Camag TLC scanner III in the absorbance-reflectance mode at $254 \mathrm{~nm}$ and operated by WINCATS software (v 1.4.3 Camag) in built in the system and concentration of the compound was determined.

Selection of detection wavelength: After the plates were developed, the bands were scanned in UV range of 200-400 $\mathrm{nm}$ and the spectra were obtained. Germacrene D, the compound under investigation showed absorbance at $235 \mathrm{~nm}$ and hence thus wavelength was selected for all the experiments and further analysis.

Germacrene D was isolated from the plant extract by micro-preparative TLC and subjected to NMR $\left({ }^{1} \mathrm{H}\right.$ NMR, ${ }^{13} \mathrm{C}$ NMR) and mass spectra for subsequent identification and characterization.
${ }^{1} \mathbf{H} \&{ }^{13} \mathbf{C}$ NMR: Both NMR i.e. ${ }^{1} \mathrm{H}$ and ${ }^{13} \mathrm{C}$ NMR spectra were recorded on Varian Gemini 200 or Varian Unity 400 in $\mathrm{CCl}_{4} / \mathrm{CDCl}_{3}$ (1:1) solvent. The internal standard employed was tetramethylsilane (TMS).

Mass spectra: A mass spectrum was obtained on Micro Mass VG 70-70H spectrometer which was operating at $70 \mathrm{eV}$ using direct inlet system.

Sample preparation: The total extract and germacrene D dissolved in dichloromethane at $1 \mathrm{mg} / \mathrm{mL}$ and $1 \mathrm{~g} / \mathrm{mL}$ concentrations, respectively were used for the analysis.

Calibration plots: Standard germacrene D $(0.5,1.0,1.5$, 2.0, 2.5, 3.0, 3.5 and $4.0 \mathrm{mg}$ ) was weighed accurately, dissolved in methanol and made separate solutions. These solutions were spotted on to the TLC plates separately $0.5,1.0,1.5,2.0,2.5$, $3.0,3.5$ and $4.0 \mathrm{~mL}$ (amounting to $1000-5000 \mathrm{ng} / \mathrm{spot}$ ) to construct a calibration curve. The data of peak area versus concentration of compound was subjected to linear regression analysis and calibration curve was obtained.

Validation: The developed HPTLC method was validated as per the International standards [9-11] using RSD (relative standard deviation) and variance analysis [11,12]. The parameters considered for validation of the method include limit if detection (LOD), limit of quantification (LOQ), precision, accuracy and robustness.

Precision and accuracy: The repeatability of analytical method was assessed by applying one time each of five solutions of every concentration of geremacrene D [11,13]. Repeatability of the system, however, was done using one solution of every concentration and each was spotted in six times [11]. The same analyst was involved in the experimentation and applied on the same plate, on the same day by using the same instrument. To assess reproducibility, one solution of every concentration was applied six times during 5 days using a different plate each day.

Robustness: The effect of different mobile phases such as dichloromethane:acetone and hexane:ethyl acetate at varying concentrations were used for testing the robustness of the method and the results were examined.

LOD and LOQ: The limit of detection (LOD) and limit of quantification (LOQ) were also evaluated for the developed method.

Recovery studies: The standard addition method was used for the recovery studies. The standard germacrene D amounting to 50,100 and $150 \%$ was added to the pre-analyzed sample solution. At each level of recovery, the experiments were carried out six times $(n=6)$.

\section{RESULTS AND DISCUSSION}

Selection and optimization of mobile phase: For selection and optimization of mobile phase, varying concentrations of dichloromethane:acetone were tried. However, dichloromethane: acetone $(9.8: 0.2 \mathrm{v} / \mathrm{v})$ gave improved characteristics of the spot and facilitated a distinct and selective separation of compound with a $R_{f}$ of $0.46 \pm 0.01$ (Figs. 1-3). Prior saturation of the chromatographic chamber with the mobile phase for $20 \mathrm{~min}$ at room temperature was done for better results.

Calibration curves: The data thus obtained was subjected to linear regression and calibration curves were constructed 


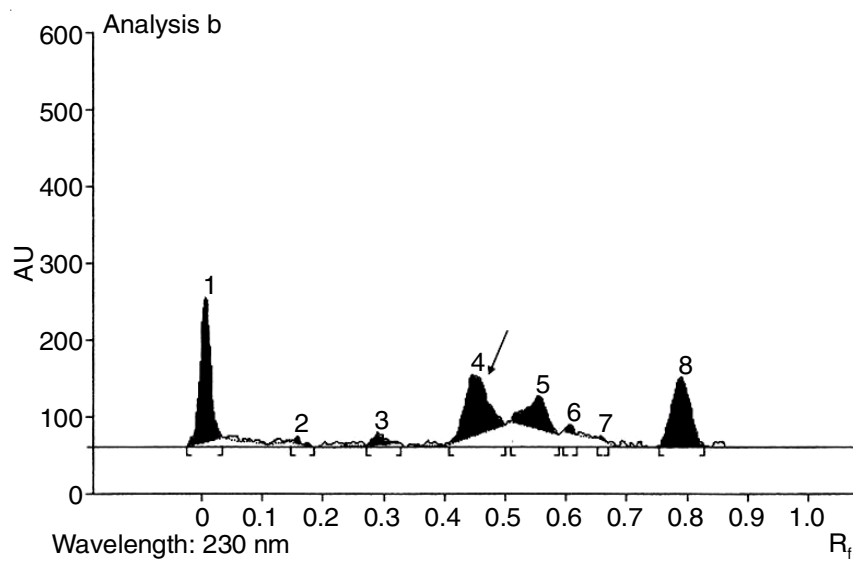

Fig. 1. HPTLC densitogram of essential oil sample from Zanthoxylum ovalifoilum

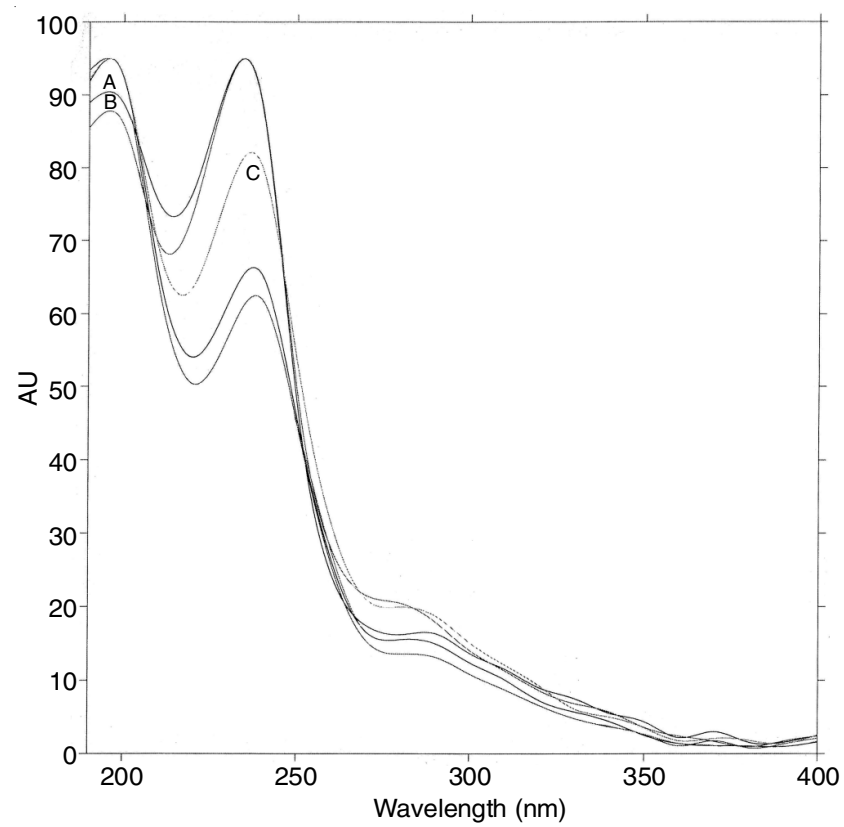

Fig. 2. UV spectra of germacrene D [A - Standard germacrene D; B germacrene $\mathrm{D}$ from plant extracts developed in dichloromethane: acetone (9.8: 0.2); C - germacrene D from plant extracts developed in hexane: ethyl acetate (8.5:1.5)]

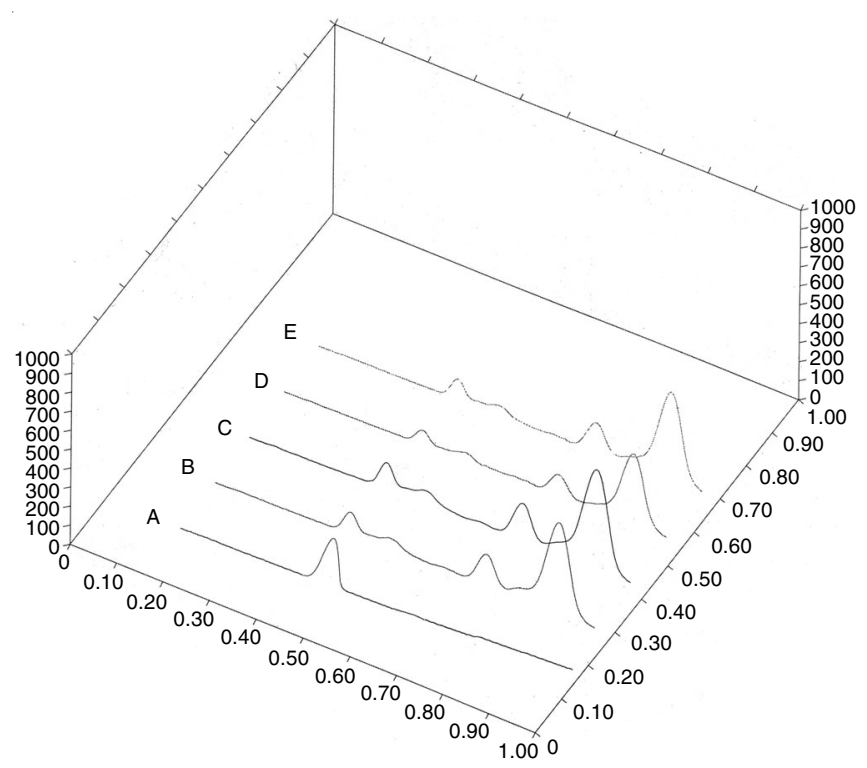

Fig. 3. Densitogram of essential oil at various concentrations $(n=6)$. It is evident from Table-1 that the method offered a good linear relationship over the concentration range of 1000$5000 \mathrm{ng}$ per spot with a correlation coefficient, $\mathrm{r}=0.9985 \pm$ 0.0004. However, the significant difference in the slopes of standard curves (ANOVA, $\mathrm{p}>0.05$ ) was not observed.

\begin{tabular}{|c|c|}
\hline \multicolumn{2}{|c|}{$\begin{array}{c}\text { TABLE-1 } \\
\text { DATA OF LINEAR REGRESSION FOR } \\
\text { CONSTRUCTION OF CALIBRATION CURVES }\end{array}$} \\
\hline Parameters & TLC densitometry \\
\hline Linearity range (ng/spot) & $1000-5000$ \\
\hline Correlation coefficient $(r) \pm S D$ & $0.9985 \pm 0.0004$ \\
\hline Slope \pm SD & $21.62 \pm 0.435$ \\
\hline Confidence limit of slope ${ }^{b}$ & $20.102-22.528$ \\
\hline Intercept \pm SD & $3308.87 \pm 10.24$ \\
\hline Confidence limit of intercept ${ }^{\mathrm{b}}$ & $3279.11-3358.24$ \\
\hline LOD (ng/spot) & 212.07 \\
\hline LOQ (ng/spot) & 521.23 \\
\hline
\end{tabular}

Validation of the method: The method developed in the present study was validated according to the $\mathrm{ICH}$ guidelines $[14,15]$. The LOD and LOQ were found to be 212.07 and $521.23 \mathrm{ng} / \mathrm{spot}$, respectively. The results obtained for the intraday and inter-day precision are shown in Table-2 and it was clearly evident that the RSD values for both repeatability and precision studies were found to be $<2 \%$, indicating that the developed method was precise as per ICH guidelines. The low values of $\%$ RSD indicate that the developed method was robust (Table-3).

\begin{tabular}{ccc|cc}
\multicolumn{5}{c}{ TABLE-2 } \\
\multicolumn{5}{c}{\begin{tabular}{c}
\multicolumn{2}{c}{ INTRA-DAY AND INTER-DAY } \\
PRECISION OF HPTLC METHOD $(\mathrm{n}=6)$
\end{tabular}} \\
\hline $\begin{array}{c}\text { Sample } \\
\text { conc. } \\
\text { (ng/spot) }\end{array}$ & \multicolumn{2}{c}{ Intra-day precision } & \multicolumn{2}{c}{ Inter-day precision } \\
\cline { 2 - 5 } & Peak area & RSD $(\%)$ & Peak area & RSD $(\%)$ \\
\hline 1000 & $1250.42 \pm 15.4$ & 1.23 & $1245.24 \pm 11.2$ & 0.87 \\
2000 & $2428.17 \pm 12.9$ & 1.03 & $2413.18 \pm 12.2$ & 0.98 \\
3000 & $3561.63 \pm 16.1$ & 0.99 & $3589.25 \pm 13.4$ & 1.34 \\
4000 & $4703.42 \pm 13.2$ & 1.09 & $4751.83 \pm 12.6$ & 1.12 \\
5000 & $5827.41 \pm 12.8$ & 1.14 & $5862.17 \pm 13.9$ & 1.07 \\
\hline
\end{tabular}

\begin{tabular}{lcc}
\multicolumn{3}{c}{ TABLE-3 } \\
ROBUSTNESS $(\mathrm{n}=6)$ \\
\hline \multicolumn{1}{c}{ Parameter } & Recovery (\%) & RSD (\%) \\
\hline Mobile Phase & & \\
1. Dichloromethane:acetone & 101.21 & 0.69 \\
2. Hexane:EtOAc & 98.42 & 0.87 \\
\hline Plate run length & & \\
$1.8 \mathrm{~cm}$ & 100.13 & 1.04 \\
$2.9 \mathrm{~cm}$ & 98.94 & 0.99 \\
\hline
\end{tabular}

Recovery studies were performed $(n=6)$ by standard addition method at 50, 100 and $150 \%$ in order to determine the accuracy of the method. The standard germacrene D of known amounts was added to pre-analyzed samples and subsequently subjected to the proposed HPTLC method and the results are presented in Table-4. Further, the specificity of the method was also assessed by analyzing standard compound and the sample. The germacrene D present in the sample was confirmed by comparing its $\mathrm{R}_{\mathrm{f}}$, NMR and mass spectra with that of standard compound and this indicated the presence of germacrene $\mathrm{D}$. 


\begin{tabular}{cccc}
\hline \multicolumn{4}{c}{ TABLE-4 } \\
RECOVERY STUDIES $(\mathrm{n}=6)$ \\
\hline $\begin{array}{c}\text { Addition of sample } \\
\text { in excess (\%) }\end{array}$ & $\begin{array}{c}\text { Theoretical } \\
\text { content }(\mathrm{ng})\end{array}$ & $\begin{array}{c}\text { Recovery } \\
(\%)\end{array}$ & RSD (\%) \\
\hline 0 & 1000 & 100 & 1.02 \\
50 & 1500 & 98.83 & 1.34 \\
100 & 2000 & 99.17 & 1.26 \\
150 & 2500 & 98.92 & 1.06 \\
\hline
\end{tabular}

Germacrene D: ${ }^{1} \mathrm{H}$ NMR $\left(200 \mathrm{MHz}, \mathrm{CDCl}_{3}\right) \delta: 5.78(\mathrm{~d}$, $2 \mathrm{H}), 5.22(\mathrm{dd}, 1 \mathrm{H}), 5.16-5.18(\mathrm{~m}, 1 \mathrm{H}), 1.96(\mathrm{~s}, 6 \mathrm{H}), 1.42-1.46$ (s, 1H), 1.01 (s, 6H), 2.22 (d, 1H); ${ }^{13} \mathrm{C} \mathrm{NMR}, 400 \mathrm{MHz}(\mathrm{ppm})$ $\delta: 135.4,131.0,128.1,125.8,107.4,40.4,36.4,34.2,31.7$, 28.1, 27.9, 23.4, 20.3, 20.3, 20.3. EI-MS (70 ev). $\mathrm{M}^{+} 204$ (12.5), 161 (100), 147 (6.9), 133 (23.6), 119 (45.8), 105 (70.8), 91 (54.2), 81 (36.0), 67 (12.5), 55 (15.3), 41 (23.6). EI-MS (70 ev). $\mathrm{M}^{+} 204$ (12.5), 161 (100), 147 (6.9), 133 (23.6), 119 (45.8), 105 (70.8), 91 (54.2), 81 (36.0), 67 (12.5), 55 (15.3), 41 (23.6).

\section{Conclusion}

Germacrene D from leaves of Zanthoxylum ovalifolium was separated and a method was developed for its analysis. The developed HPTLC method was found to be specific, precise, robust, stability indicating and accurate with excellent linearity within the tested concentrations proving that this method finds a potent application in routine quality control analysis of pharmaceutical formulations. Accuracy was optimal and remained close to $100 \%$. The low RSD values and the variance analysis indicate that the developed method has good repeatability and can be applied to all the essential oil samples in general and germacrene $\mathrm{D}$ in particular.

\section{CONFLICT OF INTEREST}

The authors declare that there is no conflict of interests regarding the publication of this article.

\section{REFERENCES}

1. B.A. McAndrew, Perfumes: Art, Science and Technology, Elsevier Applied Science: London, New York (1992).

2. K. Yoshihara, Y. Ohta, T. Sakai and Y. Hirose, Tetrahedron Lett., 10, 2263 (1969); https://doi.org/10.1016/S0040-4039(01)88136-3.

3. N. Bulow and W.A. Konig, Phytochemistry, 55, 141 (2000); https://doi.org/10.1016/S0031-9422(00)00266-1.

4. M. Telascrea, C.C. de Araújo, M.O.M. Marques, R. Facanali, P.L.R. de Moraes and A.J. Cavalheiro, Biochem. Syst. Ecol., 35, 222 (2007); https://doi.org/10.1016/j.bse.2006.09.015.

5. C. Nishino, W.S. Bowers, M.E. Montgomery, L.R. Nault and M.W. Nielson, J. Chem. Ecol., 3, 349 (1977); https://doi.org/10.1007/BF00988450.

6. S.R. Kiran, K. Bhavani, P.S. Devi, B.R. Rajeswara Rao and K.J. Reddy, Bioresour. Technol., 97, 2481 (2006); https://doi.org/10.1016/j.biortech.2005.10.003.

7. S.R. Kiran, A.S. Reddy, P.S. Devi and K.J. Reddy, Pest Manag. Sci., 62, 1116 (2006); https://doi.org/10.1002/ps.1266.

8. S.R. Kiran, P.S. Devi and K.J. Reddy, Curr. Sci., 93, 544 (2007).

9. P. Pavani, H.S. Ashwini, A. Chittaragi and R. Naika, Int. J. Pharm. Pharm. Res., 3, 323 (2015).

10. B. Singh, A.K. Uniyal and N.P. Todaria, J. Sustain. Agric., 30, 87 (2007); https://doi.org/10.1300/J064v30n03_07.

11. O. Quattrochi, S. Abelaira and R. Laba, Introducción a la HPLC. Impreso En La Argentina, Buenos Aires (1992).

12. W. Daniel, Bioestadística, Base para el análisis de las ciencias de la salud, Uteha Noriega Editores, México (1996).

13. The United States Pharmacopeia/The National Formulary (USP 25/ NF 20), United States Pharmacopeial Convection Inc., USA (2002).

14. ICH Harmonized Tripartite Guideline, Text on Validation of Analytical Procedures (1994).

15. ICH Harmonized Tripartite Guideline, Guidance on Analytical Method Validation, in: Proceedings of the International Convention on Quality for the Pharmaceutical Industry, Toronto, Canada (2002). 